\title{
TLR4 antagonist suppresses airway remodeling in asthma by inhibiting the T-helper 2 response
}

\author{
MING LI $^{1 *}$, ZHAO-NI WANG $^{2 *}$, LI-FEN YANG $^{2}$, YAN YAN $^{3}$, LIANG-MING CAI $^{2}$, \\ YA-TING LI ${ }^{2}$, YONG-KANG QIAO ${ }^{4}$ and ZHUANG-GUI CHEN ${ }^{2}$ \\ ${ }^{1}$ Department of Pulmonary Diseases, The First Affiliated Hospital of Sun Yat-Sen University, Guangzhou, \\ Guangdong 510700; ${ }^{2}$ Department of Pediatrics, The Third Affiliated Hospital of Sun Yat-Sen University, \\ Guangzhou, Guangdong 510630, P.R. China; Departments of ${ }^{3}$ Otolaryngology and ${ }^{4}$ Physiology, \\ Yong Loo Lin School of Medicine, National University of Singapore, Singapore 117597, Republic of Singapore
}

Received October 10, 2016; Accepted June 2, 2017

\section{DOI: $10.3892 /$ etm.2017.4898}

\begin{abstract}
Airway remodeling is a hallmark of bronchial asthma. Our group has previously reported that the thymic stromal lymphopoietin (TSLP), an airway epithelial-derived cytokine, has a central role in the pathogenesis of airway remodeling, and that toll-like receptor (TLR) 4 signaling in epithelial cells may trigger T-helper 2 (Th2) immune responses by overexpression of TSLP. However, it is currently unclear whether TLR4 is a target in the treatment of airway remodeling in asthma. The present study established a house dust mite (HDM)-induced chronic asthmatic model in female BALB/c mice and treated the HDM-exposed mice with $3 \mathrm{mg} / \mathrm{kg}$ TAK242, as a TLR4 antagonist, $30 \mathrm{~min}$ prior to HDM challenge for up to 2 weeks. General structural changes in the airways were subsequently evaluated and the levels of TSLP in the bronchoalveolar lavage fluid (BALF) and interleukin (IL)-4, IL-13 and interferon (IFN)- $\gamma$ in the blood serum were determined. Results indicated that TAK242 treatment markedly reduced pathological changes in the airways of HDM-induced asthmatic mice, as demonstrated by reductions in airway wall thickening, peribronchial collagen deposition and subepithelial fibrosis. Furthermore, airway hyperresponsiveness to inhaled methacholine and the levels of TSLP in the BALF and IL-4, IL-13 and IFN- $\gamma$ in the peripheral blood
\end{abstract}

Correspondence to: Professor Zhuang-Gui Chen, Department of Pediatrics, The Third Affiliated Hospital of Sun Yat-Sen University, 600 Tianhe Road, Guangzhou, Guangdong 510630, P.R. China

E-mail: chenzhuanggui@126.com

Dr Yong-Kang Qiao, Department of Physiology, Yong Loo Lin School of Medicine, National University of Singapore, 21 Lower Kent Ridge Road, Singapore 117597, Republic of Singapore E-mail: a0126767@u.nus.edu

*Contributed equally

Key words: airway remodeling, bronchial asthma, mouse model, toll-like receptor 4 antagonist, thymic stromal lymphopoietin were significantly reduced by TAK 242 treatment $(\mathrm{P}<0.05)$. Furthermore, the shift in the IFN- $\gamma / \mathrm{IL}-4$ ratio induced by HDM treatment was significantly reversed following TAK 242 pretreatment, which indicated that TAK242 modulated Th1/Th2 immune homeostasis in the chronic asthma mouse model. The present findings in a chronic asthma mouse model suggest that TAK242 may be an efficient treatment for airway remodeling, possibly through the inhibition of TSLP overexpression and Th2 airway inflammation.

\section{Introduction}

Allergic asthma is among the most common chronic lung diseases worldwide (1), of which airway remodeling is the predominant feature and primary cause of asthma-related disability and mortality $(2,3)$. However, the development of effective therapeutic agents for the treatment of airway remodeling is in its infancy (4). The current therapeutic agents used for asthma therapy include glucocorticoids, which are only effective in inhibiting airway inflammation and have a limited effect in treating airway remodeling, which is among the underlying reasons for drug-resistant asthma $(5,6)$. The identification of novel strategies that overcome the pathological airway structural changes in asthma is required. However, the mechanisms underlying the airway structural changes in asthma are not well understood and require further investigation.

It has recently been indicated that bronchial epithelial cells are critical in driving naïve $\mathrm{T}$ cell differentiation towards T-helper 2 (Th2) cells through the activation of dendritic cells (7-10). This is mediated by toll-like receptor 4 (TLR4) signaling upon the interaction of epithelial cells and environmental aero-antigens, including house dust mites (HDMs), which are the most common allergen known to induce asthma $(11,12)$. The activation of TLR4 has been demonstrated to stimulate the expression of multiple epithelium-derived cytokines, including thymic stromal lymphopoietin (TSLP) and interleukins (ILs)-25 and -33 $(13,14)$. Notably, our group has previously reported that TSLP signaling in airway epithelial cells may serve a central role in initiating airway remodeling by stimulating the Th2 cell response (15). Therefore, targeting 
of TLR4 signaling may be an effective strategy to treat airway remodeling in asthma. TAK242, as a specific TLR4 antagonist that was initially developed for sepsis therapy, is a potent anti-inflammatory drug $(16,17)$. However, the efficacy of this drug in the treatment of airway remodeling in asthma remains unknown. By establishing a HDM-induced chronic asthma mouse model, the present study investigated whether TAK242 was able to reducing pathological airway structural changes. Furthermore, the present study evaluated whether TAK242 may exert its effects by inhibiting TSLP signaling and reversing Th2/Th1 skewing in mice with chronic asthma. The outcomes of the present study may indicate a novel strategy for the treatment of chronic asthma and improve understanding of asthma pathogenesis.

\section{Materials and methods}

Animals and reagents. A total of 15 female $\mathrm{BALB} / \mathrm{c}$ mice (6-8 weeks old; weighing $18 \pm 2 \mathrm{~g}$ ) were purchased from Shanghai SLAC Laboratory Animal Center (Shanghai, China). The animals were housed under specific pathogen-free conditions under a 12-h light/dark cycle with a constant temperature of $20^{\circ} \mathrm{C}$ and humidity of $55 \%$. No dietary restriction was applied. All procedures were performed in accordance with the guidelines of the Institutional Animal Care and Use Committee of Sun Yat-sen University (Guangzhou, China). Purified HDM whole-body extract was purchased from Greer Laboratories, Inc. (Lenoir, NC, USA) and dissolved in saline for intranasal instillation. TAK242 powder was purchased from Takeda Pharmaceutical Company (Osaka, Japan) and dissolved in dimethyl sulfoxide (DMSO) prior to use. A mouse TSLP ELISA kit was purchased from R\&D Systems, Inc. (cat. no. MTLP00; Minneapolis, MN, USA), and IL-4, IL-13 and interferon (IFN)- $\gamma$ ELISA kits were purchased from eBioscience; Thermo Fisher Scientific, Inc. (cat. nos. BMS613, BMS6015, and BMS606, respectively; Waltham, MA, USA). The present study was approved by the Ethics Committee of the Third Affiliated Hospital of Sun Yat-Sen University.

HDM-induced chronic asthma model. Mice were randomly divided into saline (negative control), HDM-exposed and TAK242 treatment groups (5 mice/group). The HDM-induced chronic asthma model was established as described previously $(15,18)$ with slight modifications (Fig. 1). Briefly, following anesthesia with $2.0 \%$ isoflurane (Baxter, Deerfield, IL, USA) using a Matrx Animal Anesthesia Ventilator System (Matrx VIP3000; Midmark Corporation, Dayton, OH, USA), the mice were challenged by intranasal instillation with $15 \mu \mathrm{g}$ HDM (in $10 \mu$ l saline) every day for 3 consecutive days followed by a 4 day rest period, which was repeated over the course of 5 weeks. From week 4 onwards, $3 \mathrm{mg} / \mathrm{kg}$ TAK242 or an equivalent volume of DMSO was administered by intraperitoneal injection $30 \mathrm{~min}$ prior to HDM exposure to the TAK242 treatment group or HDM group, respectively. The negative control group was exposed to $10 \mu \mathrm{l}$ saline instead of HDM.

Whole-body plethysmograph. On day 32, $24 \mathrm{~h}$ after the final HDM intranasal administration, airway hyperresponsiveness (AHR) was measured using whole-body plethysmography

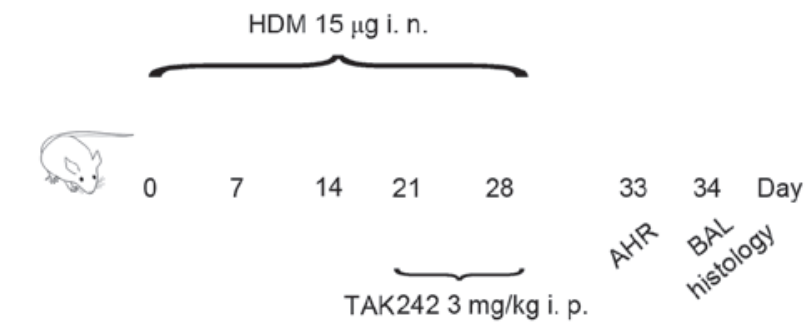

Figure 1. Establishment of HDM-induced chronic asthma model in mice. BALB/c mice were challenged by i.n. HDM on 3 consecutive days per week for 5 weeks. The negative control group was exposed to saline instead of HDM. From week 4 onwards, TAK 242 or dimethyl sulfoxide was administered by i.p. injection $30 \mathrm{~min}$ prior to HDM exposure in the TAK 242 treatment group or HDM group, respectively. On day 32 AHR to methacholine was assessed. For histological analysis, BALF and lung tissue were harvested on day 33 following the sacrifice of mice. HDM, house dust mites; AHR, airway hyperresponsiveness; BALF, bronchoalveolar lavage fluid; i.n., intranasal; i.p., intraperitoneal.

(Buxco Electronics, Inc., Wilmington, NC, USA), as described previously (15). The mice were placed in a chamber for acclimatization and the basal enhanced pause (Penh) values were recorded. Following acclimatization, saline was nebulized as a control in all groups, which was followed by administration of increasing concentrations $(6.25,12.5,25,50$ and $100 \mathrm{mg} / \mathrm{ml})$ of methacholine (Sigma-Aldrich; Merck KGaA; Darmstadt, Germany), administered at 5-min intervals. Penh values were recorded as testing values. The final Penh for each concentration was calculated using the following formula: $100 \mathrm{x}$ (testing Penh-basal Penh)/basal Penh.

Bronchoalveolar lavage fluid (BALF) collection. Mice were sacrificed with an overdose of anesthetic (by inhalation of $5.0 \%$ isoflurane) $24 \mathrm{~h}$ after the assessment of AHR. The left major bronchus was tied and inserted with a 24 -guage needle. The BALF was harvested using a $1 \mathrm{ml}$ saline perfusion, which was repeated 3 times. Following collection, the BALF was centrifuged at $600 \mathrm{x} \mathrm{g}$ for $10 \mathrm{~min}$ at $4^{\circ} \mathrm{C}$ and the supernatant was stored at $-80^{\circ} \mathrm{C}$ for TSLP measurement using ELISA kit following the manufacturer's instructions.

Cell counting. Cells in the BALF were collected via centrifugation $\left(600 \mathrm{x} \mathrm{g}, 10 \mathrm{~min}\right.$ at $\left.4^{\circ} \mathrm{C}\right)$ and then resuspended with $0.5 \mathrm{ml}$ of PBS. $0.1 \mathrm{ml}$ of the cell suspension was used for total cell counting in a hemocytometer. The remaining cell suspension was smeared onto the glass slides. The Wright-Giemsa staining were performed on the dry-out slides and the eosinophils were identified and counted in every 400 cells (percentage of eosinophils=numbers of eosinophils/400x 100\%) (15).

Lung histology. The left lung lobes of the mice were harvested, fixed in $4 \%$ neutral buffered formalin at room temperature overnight and embedded in paraffin. Lung sections were prepared by sectioning the tissue into $5-\mu \mathrm{m}$ thick sections. Hematoxylin and eosin staining was performed to evaluate the general structural changes of the airways, and periodic acid-Schiff and Masson's trichrome staining were performed on the lung sections to visualize goblet cells and collagen deposition, respectively, using a light microscope. The goblet 


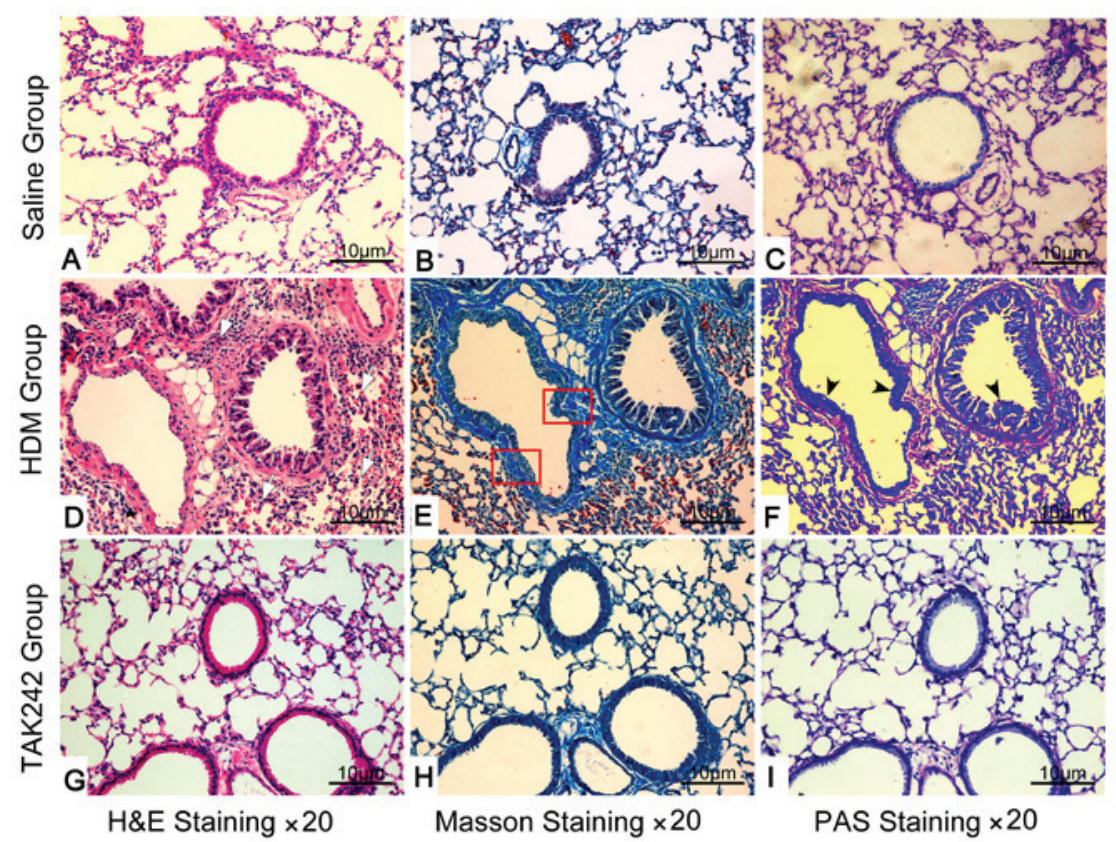

Figure 2. (A-I) TAK242 treatment ameliorated pathological airway structural changes in chronic asthmatic mice. (A, D and G) H\&E staining was performed to evaluate the general structural changes of the airways, and (B, E and H) Masson's thichrome and (C, F and I) PAS staining was conducted on the lung sections to visualize collagen deposition and goblet cells, respectively. Magnification, x20. The white arrows indicate the inflammatory cell infiltration, red frames indicate thickened airway walls, peribronchial collagen deposition and subepithelial fibrosis, and the black arrowheads indicate goblet cell hyperplasia. H\&E, hematoxylin and eosin; HDM, house dust mites; PAS, periodic acid-schiff.

cell coverage and peribronchial collagen thickness were measured as described previously (15).

Peripheral blood collection and ELISA. After the mice were sacrificed, a capillary was inserted into the medical canthus of the eye with slight pressure. The peripheral blood was harvested through the capillary tube to obtain a total volume of 0.8-0.9 ml. Following clot formation, the blood was centrifuged at $600 \mathrm{x} \mathrm{g}$ for $10 \mathrm{~min}$ at $4^{\circ} \mathrm{C}$ and the serum was stored at $-80^{\circ} \mathrm{C}$ to measure cytokine levels. ELISA was performed to determine the levels of IL-4, IL-13 and IFN- $\gamma$ in the peripheral blood following the manufacturer's instructions.

Statistical analysis. Data were analyzed using SPSS 21.0 software (IBM Corp., Armonk, NY, USA) and presented as the mean \pm standard deviation. Statistical analysis was performed using one-way analysis of variance for multiple comparisons followed by a Fisher's least significant difference post hoc test with homoscedasticity, or a Welch's approximate t-test followed by a Dunnett's T3 test with heterogeneity of variance. $\mathrm{P}<0.05$ was considered to indicate a statistically significant difference.

\section{Results}

TAK242 treatment inhibits airway structural changes in HDM-exposed mice. As indicated in Fig. 2, mice exposed to HDM exhibited marked airway structural changes when compared with the saline group (Fig. 2A-F), including inflammatory cell infiltration (Fig. 2D), thickened airway walls, peribronchial collagen deposition, subepithelial fibrosis (Fig. 2E) and goblet cell hyperplasia (Fig. 2F). Notably, TAK242 treatment abolished these airway structural changes induced by HDM treatment (Fig. 2G-I), which indicated that TAK242 may be efficient in the treatment of airway remodeling. Furthermore, the numbers of total cells and eosinophils in the BALF, and the coverage of airway goblet cells, were significantly reduced in TAK242-treated mice compared with HDM-exposed mice ( $\mathrm{P}<0.01$; Fig. 3).

TAK242 pretreatment reduces AHR levels in chronic asthmatic mice. AHR is a clinical sign of chronic asthma, and is characterized by hyperreactivity of the airways in response to relatively low concentrations of bronchial constricting reagents, including methacholine (19). Whole-body plethysmographs demonstrated that the airway reactivity levels of HDM-exposed mice were significantly increased when compared with the saline group at the concentration of $100 \mu \mathrm{g} / \mathrm{ml}(\mathrm{P}<0.01)$, which suggested successful establishment of the chronic asthma model. Notably, TAK242 pretreatment significantly reduced the Penh levels in HDM-exposed mice when compared with the HDM group at the concentration of $100 \mu \mathrm{g} / \mathrm{ml}(\mathrm{P}<0.01$; Fig. 4), which further demonstrated that TAK 242 may be efficient in treating asthma.

TAK242 inhibits TSLP expression in the chronic asthma model. Our group previously demonstrated that TSLP signaling in airway epithelial cells mediated airway remodeling in asthma (15). To evaluate whether TAK242 blocked airway remodeling through the inhibition of TSLP signaling, TSLP levels in the BALF were measured (Fig. 5). The results indicated that TAK242 significantly reduced the levels of TSLP from $25.32 \pm 1.92 \mathrm{pg} / \mathrm{ml}$ in HDM-exposed mice to $17.82 \pm 1.42 \mathrm{pg} / \mathrm{ml}$ in TAK242-treated mice $(\mathrm{F}=8.391 ; \mathrm{P}<0.05)$, which was similar to the TSLP levels in the saline group $(16.33 \pm 1.67 \mathrm{pg} / \mathrm{ml})$. 

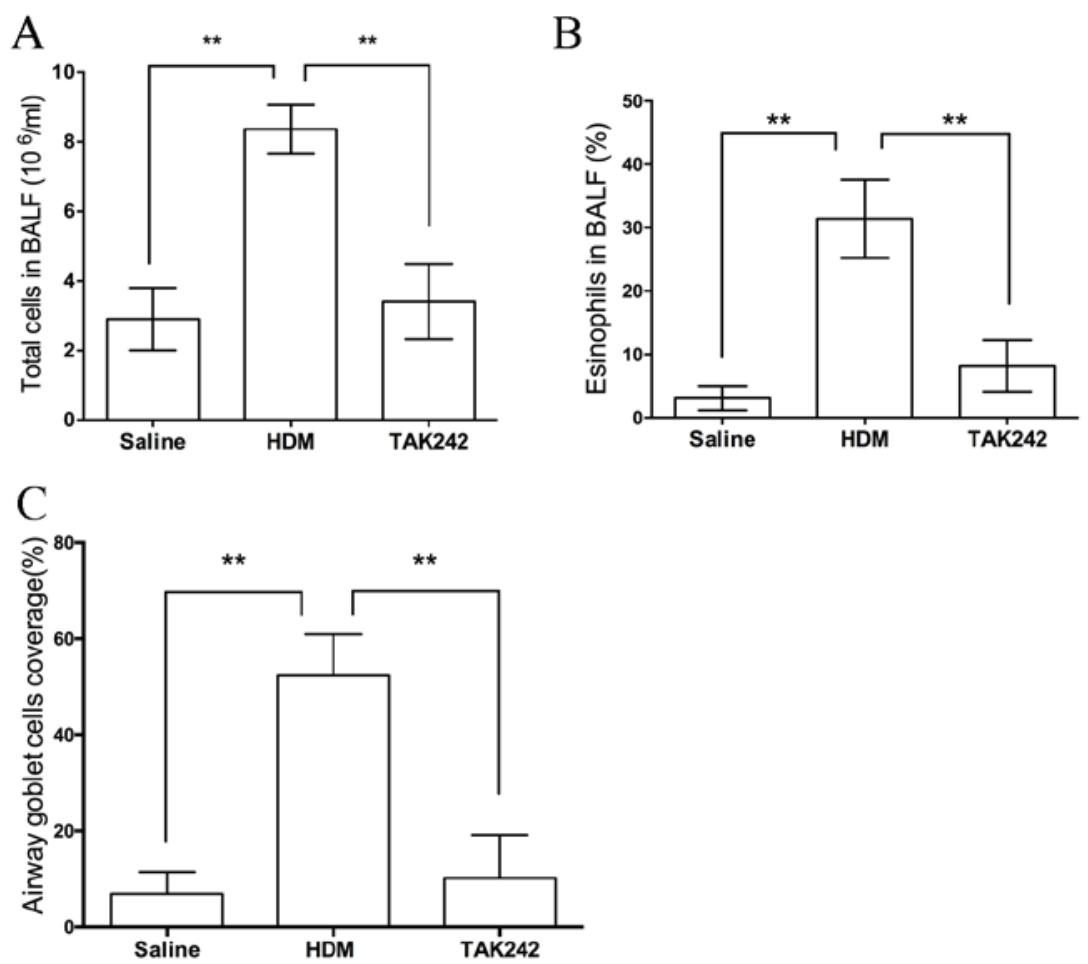

Figure 3. TAK242 treatment reduced pathological cell changes in chronic asthmatic mice. Cell counting of the (A) total cells and (B) eosinophils in the BALF, and $(\mathrm{C})$ the coverage of airway goblet cells in mice. ${ }^{* *} \mathrm{P}<0.01$. HDM, house dust mites; BALF, bronchoalveolar lavage fluid.

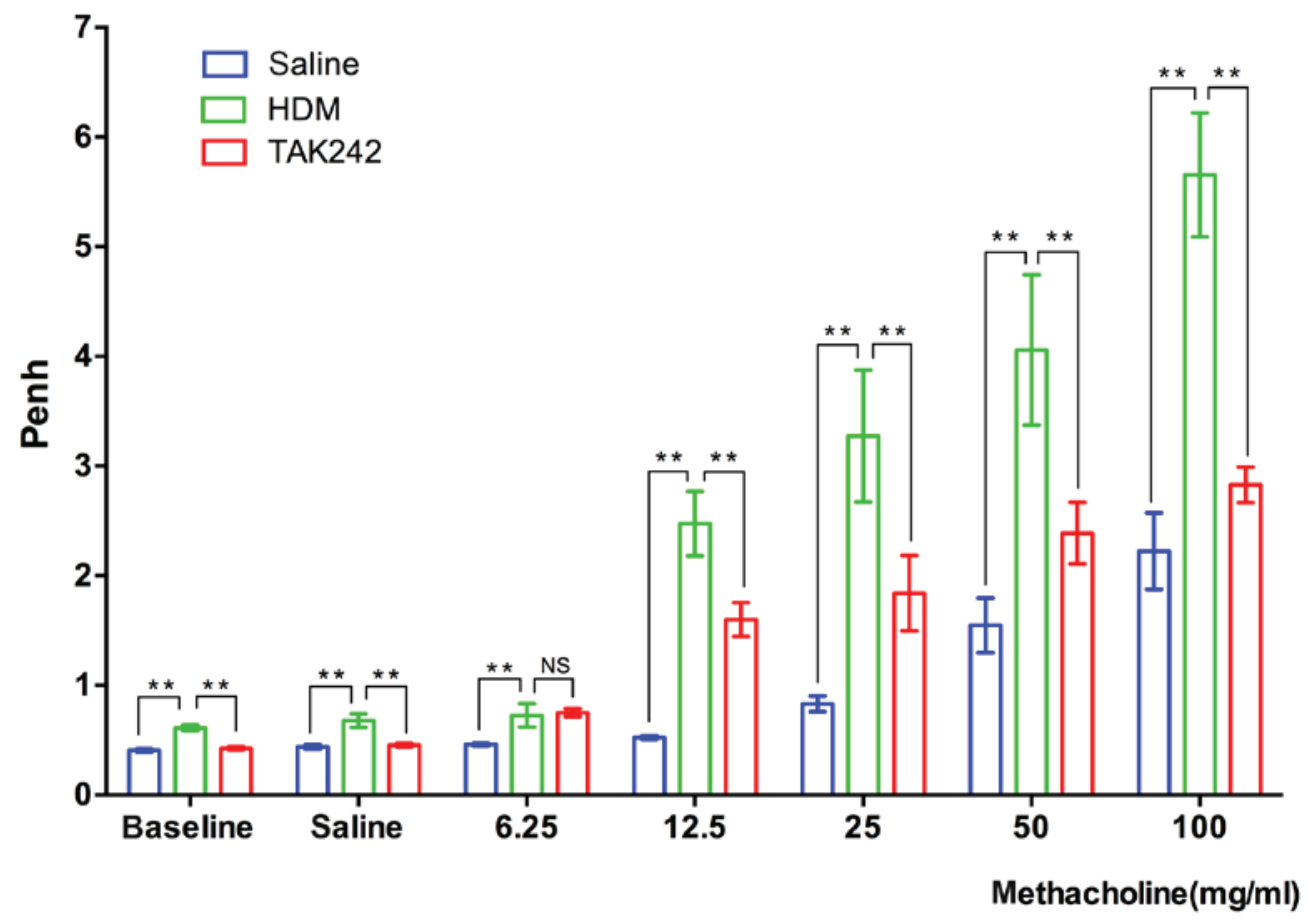

Figure 4. TAK242 treatment reduced HDM-induced airway hyperreactivity. The Penh of mice was recorded following stimulation with increasing concentrations $(0,6.25,12.5,25,50$ and $100 \mathrm{mg} / \mathrm{ml})$ of methacholine. Data are presented as the mean \pm standard deviation. ${ }^{* *} \mathrm{P}<0.01$ vs. HDM group. HDM, house dust mites.

TAK242 reduces Th2 cytokine expression and reverses Th2/Th1 skewing. Th2/Th1 skewing is a central event that aids to trigger pathological changes in asthma, and is initiated by TSLP signaling (20). Therefore, the potential inhibitory effect of TAK242 against the Th2 cell response was determined by measuring levels of the Th2-type cytokines IL-4, IL-13 and Th1-cytokine IFN- $\gamma$ in the peripheral blood. ELISA results indicated that TAK242 signficantly reduced the levels of all 
Table I. Effect of TAK242 treatment on the levels of Th1/Th2 cytokines.

Statistical values

\begin{tabular}{|c|c|c|c|c|c|c|c|}
\hline \multirow[b]{3}{*}{ Cytokine } & \multirow{2}{*}{\multicolumn{3}{|c|}{ Group $(n=5)$}} & \multirow{2}{*}{\multicolumn{2}{|c|}{ HDM vs. Saline }} & & \\
\hline & & & & & & \multicolumn{2}{|c|}{ HDM vs. TAK 242} \\
\hline & Saline & HDM & TAK242 & F-value & P-value & F-value & P-value \\
\hline $\mathrm{IFN}-\gamma(\mathrm{pg} / \mathrm{ml})$ & $21.46 \pm 4.23$ & $52.45 \pm 9.86$ & $25.87 \pm 3.81$ & 6.459 & 0.0002 & 5.623 & 0.0005 \\
\hline IL-4 (pg/ml) & $10.23 \pm 2.38$ & $48.78 \pm 7.24$ & $14.14 \pm 1.62$ & 11.31 & 0.0000 & 10.44 & 0.0000 \\
\hline IL-13 (pg/ml) & $31.46 \pm 2.96$ & $78.75 \pm 5.83$ & $42.89 \pm 5.98$ & 16.17 & 0.0000 & 9.601 & 0.0000 \\
\hline IFN- $\gamma / \mathrm{IL}-4$ & $2.10 \pm 0.15$ & $1.10 \pm 0.27$ & $1.82 \pm 0.35$ & 7.240 & 0.0001 & 3.642 & 0.0066 \\
\hline
\end{tabular}

The concentrations of Th1/Th2 cytokines in the saline, HDM and TAK242 groups are presented as the mean \pm standard deviation. $\mathrm{P}<0.05$ was considered to indicate a statistically significant difference. Th, T-helper; HDM, house dust mites; F-value, Fisher's post hoc F-statistic; IFN- $\gamma$, interferon- $\gamma$; IL, interleukin.

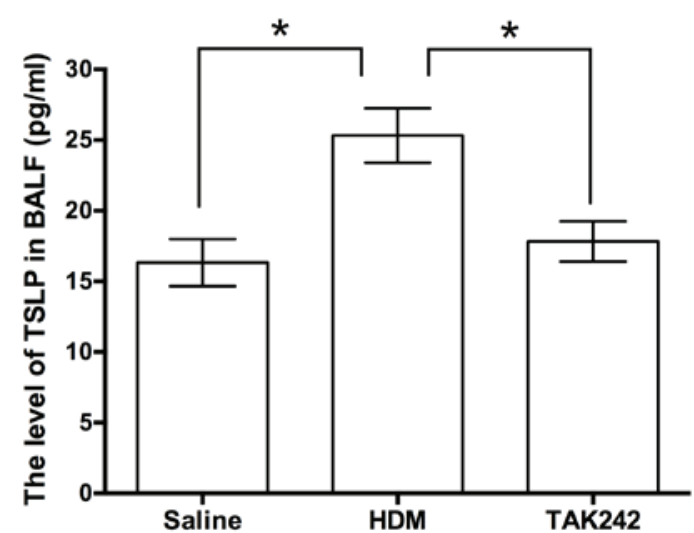

Figure 5. The level of TSLP in BALF. Data are presented as the mean \pm standard deviation. ${ }^{*} \mathrm{P}<0.05$. HDM, house dust mites; BALF, bronchoalveolar lavage fluid; TSLP, thymic stromal lymphopoietin.

cytokines when compared with those in HDM-exposed mice $(\mathrm{P}<0.01$; Table I). Notably, TAK242 significantly reversed the IFN- $\gamma /$ IL-4 ratio from $1.10 \pm 0.27$ to $1.82 \pm 0.35(\mathrm{P}=0.0066$; Table I), indicating that TAK242 may prevent IFN- $\gamma / \mathrm{IL}-4$ skewing, potentially through targeting of TLR4 signaling.

\section{Discussion}

In the present study, a HDM-induced chronic asthma mouse model was successfully established with high levels of IL-4 and IL-13, which indicated a robust Th2 response (21). This prolonged exposure model exhibited airway inflammation and structural changes characteristic of chronic asthma, including infiltration of inflammatory cells in the airway, thickened basement membranes, upregulated goblet cells within the bronchial epithelia and AHR to methacholine, thus providing a useful tool for the development of therapeutic drugs against chronic asthma.

The specific TLR4 antagonist TAK242, initially developed for sepsis therapy, has been previously demonstrated to reduce lipopolysaccharide-induced inflammation in epithelial cells $(16,17)$. However, to the best of our knowledge, the present study is the first to indicate the potential of TAK242 in the treatment of asthma. Previous studies have suggested that defects in the repair of bronchial epithelial cells may be an initiating factor for subepithelial changes in asthma $(20,22,23)$. Furthermore, the interaction of epithelial cells with allergens, including that with HDM mediated by TLR4, may initiate the Th2 immune response by inducing the secretion of epithelim-derived cytokines, including TSLP, IL-25 and IL-33, via nuclear factor- $\kappa \mathrm{B}$ activation $(7,24,25)$. This effect may be sufficient to activate dendritic cells and promote Th2/Th1 skewing $(10,26)$. Notably, our group previously demonstrated in a HDM-mouse model that TSLP signaling was a principle determinant of airway remodeling, by inducing dentritic cell activation and the Th2 immune response (15). Furthermore, blocking of TSLP reduced the levels of IL-13 and transforming growth factor- $\beta$, and reversed the pathological airway changes induced by HDM exposure. These findings suggest that TAK242 may be an effective treatment for airway remodeling through its targeting of TLR4-TSLP signaling.

Histological analyses demonstrated that TAK242 markedly alleviated pathological changes in the airways induced by HDM exposure, including thickening of the airway walls, peribronchial collagen deposition and subepithelial fibrosis, which implicates TAK242 as a potent therapeutic agent for airway remodeling in asthma. To investigate the underlying mechanisms, the levels of TSLP and Th1/Th2 cytokines were determined in all experimental groups, and the results suggested that TSLP in the BALF was significantly reduced. This finding was consistent with previous observations that TLR4 activation induced Th2-derived airway inflammation by inducing epithelium-derived cytokines, including $\operatorname{TSLP}(7,8,23)$. In addition, the IFN- $\gamma / \mathrm{IL}-4$ ratio, which reflects the Th1/Th2 immune homeostasis status in vivo (26), was significantly reversed by TAK 242 treatment in HDM-exposed mice in the present study.

As neutralizing TSLP may regulate the homeostasis of Th1/Th2, the modulatory effect of TAK242 on the Th1/Th2 balance may be a consequence of TSLP regulation and dendritic cell activation. Further studies are now required to understand the mechanism of action of TAK242 in vitro and in vivo.

In conclusion, the present results indicate that TAK242 exerts potent therapeutic effects against airway remodeling induced by allergens. These findings may aid to identify novel therapeutic strategies for the treatment of asthma and other 
lung diseases characterized by TLR4-mediated changes in airway structure.

\section{Acknowledgements}

The present study was supported by the Science and Technology Planning Project of Guangdong Province (grant nos. 2012B031800096 and 2014A020212120) and the National Natural Science Foundation of China (grant no. 81470219).

\section{References}

1. Croisant S: Epidemiology of asthma: Prevalence and burden of disease. Adv Exp Med Biol 795: 17-29, 2014

2. Vignola AM, Kips J and Bousquet J: Tissue remodeling as a feature of persistent asthma. J Allergy Clin Immunol 105: 1041-1053, 2000.

3. Tillie-Leblond I, de Blic J, Jaubert F, Wallaert B, Scheinmann P and Gosset P: Airway remodeling is correlated with obstruction in children with severe asthma. Allergy 63: 533-541, 2008.

4. Hirota N and Martin JG: Mechanisms of airway remodeling. Chest 144: 1026-1032, 2013.

5. Lo CY, Michaeloudes C, Bhavsar PK, Huang CD, Wang $\mathrm{CH}$, Kuo HP and Chung KF: Increased phenotypic differentiation and reduced corticosteroid sensitivity of fibrocytes in severe asthma. J Allergy Clin Immunol 135: 1186-1195, 2015.

6. Bateman ED, Boushey HA, Bousquet J, Busse WW, Clark TJ, Pauwels RA and Pedersen SE; GOAL Investigators Group: Can guideline-defined asthma control be achieved? The gaining optimal asthma control study. Am J Respir Crit Care Med 170: 836-844, 2004.

7. Hammad H, Chieppa M, Perros F, Willart MA, Germain RN and Lambrecht BN: House dust mite allergen induces asthma via Toll-like receptor 4 triggering of airway structural cells. Nat Med 15: 410-416, 2009.

8. Ryu JH, Yoo JY, Kim MJ, Hwang SG, Ahn KC, Ryu JC, Choi MK, Joo JH, Kim CH, Lee SN, et al: Distinct TLR-mediated pathways regulate house dust mite-induced allergic disease in the upper and lower airways. J Allergy Clin Immunol 131: 549-561, 2013.

9. Holgate ST, Roberts G, Arshad HS, Howarth PH and Davies DE: The role of the airway epithelium and its interaction with environmental factors in asthma pathogenesis. Proc Am Thorac Soc 6: 655-659, 2009.

10. Soumelis V, Reche PA, Kanzler H, Yuan W, Edward G, Homey B, Gilliet M, Ho S, Antonenko S, Lauerma A, et al: Human epithelial cells trigger dendritic cell mediated allergic inflammation by producing TSLP. Nat Immunol 3: 673-680, 2002.

11. Dust mite allergens and asthma-a worldwide problem. J Allergy Clin Immunol 83: 416-427, 1989.
12. Johnson JR, Wiley RE, Fattouh R, Swirski FK, Gajewska BU, Coyle AJ, Gutierrez-Ramos JC, Ellis R, Inman MD and Jordana M: Continuous exposure to house dust mite elicits chronic airway inflammation and structural remodeling. Am J Respir Crit Care Med 169: 378-385, 2004.

13. Bartemes KR and Kita H: Dynamic role of epithelium-derived cytokines in asthma. Clin Immunol 143: 222-235, 2012.

14. Allakhverdi Z, Comeau MR, Jessup HK, Yoon BR, Brewer A, Chartier S, Paquette N, Ziegler SF, Sarfati M and Delespesse G: Thymic stromal lymphopoietin is released by human epithelial cells in response to microbes, trauma, or inflammation and potently activates mast cells. J Exp Med 204: 253-258, 2007.

15. Chen ZG, Zhang TT, Li HT, Chen FH, Zou XL, Ji JZ and Chen H: Neutralization of TSLP inhibits airway remodeling in a murine model of allergic asthma induced by chronic exposure to house dust mite. PLoS One 8: e51268, 2013.

16. Rice TW, Wheeler AP, Bernard GR, Vincent JL, Angus DC, Aikawa N, Demeyer I, Sainati S, Amlot N, Cao C, et al: A randomized, double-blind, placebo-controlled trial of TAK-242 for the treatment of severe sepsis. Crit Care Med 38: 1685-1694, 2010.

17. Meijvis SC, van de Garde EM, Rijkers GT and Bos WJ: Treatment with anti-inflammatory drugs in community-acquired pneumonia. J Intern Med 272: 25-35, 2012.

18. Shikotra A, Choy DF, Ohri CM, Doran E, Butler C, Hargadon B, Shelley M, Abbas AR, Austin CD, Jackman J, et al: Increased expression of immunoreactive thymic stromal lymphopoietin in patients with severe asthma. J Allergy Clin Immunol 129: 104-111, 2012.

19. Cockcroft DW: Direct challenge tests: Airway hyperresponsiveness in asthma: Its measurement and clinical significance. Chest 138 (2 Suppl): 18S-24S, 2010.

20. Ziegler SF: Thymic stromal lymphopoietin and allergic disease. J Allergy Clin Immunol 130: 845-852, 2012.

21. Voehringer D, Reese TA, Huang X, Shinkai K and Locksley RM: Type 2 immunity is controlled by IL-4/IL-13 expression in hematopoietic non-eosinophil cells of the innate immune system. J Exp Med 203: 1435-1446, 2006.

22. Royce SG, Li X, Tortorella S, Goodings L, Chow BS, Giraud AS Tang ML and Samuel CS: Mechanistic insights into the contribution of epithelial damage to airway remodeling. Novel therapeutic targets for asthma. Am J Respir Cell Mol Biol 50: 180-192, 2014.

23. Lambrecht $\mathrm{BN}$ and Hammad $\mathrm{H}$ : Asthma: The importance of dysregulated barrier immunity. Eur J Immunol 43: 3125-3137, 2013.

24. Schuliga M: NF-kappaB signaling in chronic inflammatory airway disease. Biomolecules 5: 1266-1283, 2015.

25. Li DQ, Zhang L, Pflugfelder SC, De Paiva CS, Zhang X, Zhao G, Zheng X, Su Z and Qu Y: Short ragweed pollen triggers allergic inflammation through Toll-like receptor 4-dependent thymic stromal lymphopoietin/OX40 ligand/OX40 signaling pathways. J Allergy Clin Immunol 128: 1318-1325, 2011.

26. Onoé K, Yanagawa Y, Minami K, Iijima N and Iwabuchi K: Th1 or Th2 balance regulated by interaction between dendritic cells and NKT cells. Immunol Res 38: 319-332, 2007. 